\title{
Rich environments for active learning:
}

\section{a definition}

\author{
R. Scott Grabinger and Joanna C. Dunlap \\ University of Colorado at Denver
}

Rich Environments for Active Learning, or REALs, are comprehensive instructional systems that evolve from and are consistent with constructivist philosophies and theories. To embody a constructivist view of learning. REALs:

- promote study and investigation within authentic contexts;

- encourage the growth of student responsibility, initiative, decision making, and intentional learning;

- cultivate collaboration among students and teachers;

- utilize dynamic, interdisciplinary, generative learning activities that promote higher-order thinking processes to help students develop rich and complex knowledge structures; and

- assess student progress in content and learning-to-learn within authentic contexts using realistic tasks and performances.

REALs provide learning activities that engage students in a continuous collaborative process of building and reshaping understanding as a natural consequence of their experiences and interactions within learning environments that authentically reflect the world around them. In this way, REALs are a response to educational practices that promote the development of inert knowledge, such as conventional teacher-10-student knowledge-transfer activities.

In this article, we describe and organize the shäred elements of REALs, including the theoretical foundations and instructional strategies to provide a common ground for discussion. We compare existing assumptions underlying education with new assumptions that promote problem-solving and higher-level thinking. Next, we examine the theoretical foundation that supports these new assumptions. Finally, we describe how REALs promote these new assumptions within a constructivist framework, defining each $R E A L$ attribute and providing supporting examples of $R E A L$ strategies in action.

\section{Introduction}

In today's complex world, simply knowing how to use tools and knowledge in a single domain is not sufficient to remain competitive as either individuals or companies. People must also learn to apply tools and knowledge in new domains and different situations. Industry specialists report that people at every organizational level must be creative and flexible problem solvers (Lynton, 1989). This requires the ability to apply experience and 
knowledge to address novel problems. Consequently, learning to think critically, to analyse and synthesize information to solve technical, social, economic, political, and scientific problems, and to work productively in groups are crucial skills for successful and fulfilling participation in our modern, competitive society.

The purpose of this article is to describe and organize the shared elements of Rich Environments for Active Learning, or REALs, including the theoretical foundations and instructional strategies to provide a common ground for discussion. REALs are based on constructivist values and theories including 'collaboration, personal autonomy, generativity, reflectivity, active engagement, personal relevance, and pluralism' (Lebow, 1993 , p. 5). REALs provide learning activities that, instead of transferring knowledge to students, engage students in a continuous collaborative process of building and reshaping understanding as a natural consequence of their experiences and authentic interactions with the world (Goodman, 1984; Forman and Pufall, 1988; Fosnot, 1989). Advocating a holistic approach to education, REALs reflect, ${ }_{7}$ the assumption that the process of knowledge acquisition is 'firmly embedded in the social and emotional context in which learning takes place' (Lebow, 1993, p. 6).

\section{Need for educational change}

\section{Changing society}

Education is receiving increasing pressure from changing global economic circumstances and complex societal needs. Yet, according to Lynton (1989, p. 23), 'at this time [...] education is far from fully contributing to the economic well-being of this country [United States]'. Public and private institutions are demanding employees who can think critically and solve a range of problems, who can move easily from task to task, and who can work efficiently and effectively in team situations; yet they claim that those people are difficult to find.

The US education system, to its credit, is neither deaf to this plea nor ignorant of the need to change how and what instruction is delivered in the classroom. Calls for restructuring the way students learn come from a variety of institutions including the American Association for the Advancement of Science (1989) and the National Council of Teachers for Mathematics (1989). Educators agree that students must learn to solve problems and think independently (Feuerstein, 1979; Mann, 1979; Segal et al, 1985; Linn, 1986; Resnick and Klopfer, 1989; Bransford et al, 1990). The challenge for educators is to utilize strategies that teach content in ways that also help to develop thinking, problem-solving, metacognitive, and life-long learning skills (Bransford et al, 1990; Savery and Duffy, 1994).

\section{Weaknesses within the current system}

There is considerable evidence that today's students are not particularly strong in the areas of thinking and reasoning (Resnick, 1987; Nickerson, 1988; Bransford et al, 1991). Bransford et al (1990, pp. 115-16) state that the 'basic problem is that traditional instruction often fails to produce the kinds of transfer to new problem-solving situations that most educators would like to see'. Conventional instruction often utilizes simplified, decontextualized examples and problems, leading to an inadequate understanding of and 
ability to apply the knowledge acquired. Students often are not exposed to examples and problems that make knowledge relevant to them (Collins et al, 1991). Instead, students are asked to solve problems that cause them to wonder: 'Why do I need to know this?'. Because the information presented to students has no relevance or meaning for them, they tend to treat new information as facts to be memorized and recited rather than as tools to solve problems relevant to their own needs (Bransford et al, 1990). This, unfortunately, leads to inert knowledge - knowledge that cannot be applied to real problems and situations.

Inert knowledge

Research shows that knowledge learned but not explicitly related to relevant problemsolving remains inert (Whitehead, 1929; Perfetto et al, 1983, CTGV, 1993c). Whitehead first coined the phrase inert knowledge in 1929 to refer to knowledge acquired in abstract circumstances without direct relevance to the learner's needs. Inert knowledge is not readily available for application or transfer to novel situations (for a review of transfer research, refer to Clark and Voogel, 1985; Butterfield and Nelson, 1989). It seems that our educational system is focused on producing inert knowledge. The Cognition and Technology Group at Vanderbilt (CTGV) (CTGV, 1993c) specifies the following flaws in our conventional approaches to schooling and teaching that lead to inert knowledge:

- There is a constant battle of breadth versus depth - and breadth usually wins. We (educators) tend to fill our students with facts, and leave no time for dealing with topics in depth. We expect our students to remember dates, formulae, algorithms, quotations, and whole poems, yet show little practical use for that knowledge despite the fact that we know our students have difficulty transferring the knowledge. Robertson (1990) states that:

Students who rely on memorized algorithms for solving problems typically do not perform as well on transfer problems as do students who rely on an understanding of the underlying concepts. (p. 253)

- We consistently rely on decontextualized instructional strategies. In our desire to cover as much material as possible, we focus our instructional activities on abstract basic skills, concepts, and technical definitions. We believe that decontextualized skills have broad applicability and are unaffected by the activities or environments in which they are acquired and used (Brown et al, 1989). However, when we do this, students do not learn when to apply those skills or within what kinds of contexts they work. We do this despite a large body of evidence that indicates that abstracted skills are seldom transferred from one domain to another (Clark and Voogel, 1985; Butterfield and Nelson, 1989). We fail to realize that abstracted skills have no contextual cues to relate to new situations.

- When we do provide practice for our students, we give them arbitrary, uninteresting, unrealistic problems to solve. The example of story problems in mathematics is overused. We can also find examples of unrealistic and over-simplified problems in the sciences, languages, and social studies. Again, we do this in the mistaken belief that we must emphasize decontextualized skills that are applicable everywhere. Yet these unrealistic problems have no meaning to the students who then fail to find any contextual cues to relate to problems they may encounter in their lives. 
- We treat students passively for 12 to 16 years, rarely giving them the opportunity to take responsibility for their own learning, to explore ideas of their own choosing, to collaborate with one another or with teachers, or to make valuable contributions to the learning of others. They do not learn to take'charge of their own learning, nor do they learn the skills necessary to become life-long learners and daily problem-solvers.

To the preceding four items cited in the CTGV article, we add a couple more to the list of conventional educational practices that foster the production of inert knowledge:

- Students are not evaluated in authentic ways. After teaching in decontextualized ways, we test in the same ways. We do not look at actual performance but use paper-pencil tests to measure the quantity of knowledge learned. We fail to examine the quality of their thinking or problem-solving.

- Finally, our current school practices often have negative effects on the morale and motivation of students. Perelman (1992) states:

Students are forced to compete to achieve as much as they can within the periods of time allotted for each activity. This design requires that most students fail or do less well most of the time so that a minority of them can be labelled 'excellent.' The main functional focus of the system is not 'learning,' it is 'screening out'. (p. 72)

This has a tremendous effect on society. Drop-out rates are higher than our society can afford. We have created an evaluation, testing, and grading sub-structure that helps perpetuate the view that education is a game that has few winners and many losers. This game teaches our students to focus on tests and grades rather than on problem-solving, applying knowledge, and working collaboratively in a risk-free environment. The best students learn early on that they succeed best by working by themselves as quickly as possible. They learn to beat the tests and win the game.

\section{Erroneous assumptions}

We begin to change these conventional practices by calling into question some of our basic assumptions. Berryman (1991) states that the educational practices described above stem from five erroneous assumptions about learning that have governed education since the beginning of the industrial age. He holds that we often assume incorrectly that:

- people easily transfer learning from one situation to another if they have learned the fundamental skills and concepts [decontextualized];

- learners are 'receivers' of knowledge in verbal forms from books, experts, and teachers;

- learning is entirely behaviouristic, involving the strengthening of bonds between stimuli and correct responses;

- learners are blank slates ready to be written upon and filled with knowledge; and

- skills and knowledge are best acquired independent of realistic contexts.

To begin to address the issues of transfer and instructional methods to meet employer and societal needs, reasoning and problem-solving skill development must be a part of an interdisciplinary program of study in education (Lynton and Elman, 1987) - a program 
or environment that places students in situations where they can practise solving problems in a meaningful and constructive manner.

\section{We need to look at other ways}

One view of an alternative framework comes from researchers who are beginning to emphasize the importance of anchoring or situating instruction in meaningful problemsolving environments (CTGV, 1993c). The Cognition and Technology Group at Vanderbilt is a leader in the development of alternative frameworks of instruction and schooling. The group posits two significant changes.

First, we as educators must establish new goals for learning. We must move from emphasizing decontextualized reading and computational skills to developing independent thinkers and learners who engage in life-long learning. This does not mean that we abandon the important skills of reading and computation; it means instead that we should be teaching reading and computation within more situated contexts that demonstrate the value of those skills.

New assumptions about leaming

Second, in contrast to our long operative conventional assumptions (see above), we must base our teaching on new assumptions about the nature of thinking, learning, and instruction. We must accept that

[.. . ] the mere accumulation of factual or declarative knowledge is not sufficient to support problem solving. In addition to factual or declarative knowledge, students must learn why, when, and how various skills and concepts are relevant. (CTGV, 1993c, p. 79)

Effective problem-solving and thinking are not based solely on motivation and knowledge of thinking strategies, but also on well-organized and indexed content knowledge. Learners must have rich knowledge structures with many contextual links to help them address and solve complex problems. This means that instead of trying to abstract a set of decontextualized general skills, we must make our teaching as contextualized as possible to provide as many possible links with other domains as possible.

Therefore, we propose the following 'new' assumptions about learning and teaching:

- People transfer learning from one situation to another with difficulty. Learning is more likely to be transferred from complex and rich learning situations. Rich learning activities help students think deeply about content in relevant and realistic contexts (CTGV, 1993c).

- Learners are 'constructors' of knowledge in a variety of forms. They take an active role in forming new understandings and are not just passive receptors.

- Learning is a collaborative process. Students learn not solely from experts and teachers, but also from each other. They test ideas with each other and help each other build elaborate and refined knowledge structures.

- Learning is cognitive, and involves the processing of information and the constant creation and evolution of knowledge structures. We must focus on and make visible thinking and reasoning processes. We are not suggesting abandoning the teaching of 
content to teach only thinking and reasoning, because 'knowledge of concepts, theories, and principles [. . .] empowers people to think effectively' (Bransford et al, 1990 , p. 115).

- Learners bring their own needs and experiences to a learning situation and are ready to act according to those needs. We must incorporate those needs and experiences into learning activities to help students take ownership and responsibility for their own learning.

- Skills and knowledge are best acquired within realistic contexts. Morris et al (1979) call this 'transfer appropriate processing.' Transfer appropriate processing means that students must have the opportunity to practise and learn the outcomes that are expected of them under realistic or authentic conditions.

- Assessment of students must take more realistic and holistic forms, utilizing projects and portfolios and de-emphasizing standardized testing. Educators are increasingly aware that conventional achievement and intelligence tests do not measure the ability of people to perform in everyday settings and adapt to new situations (CTGV, 1993c).

A discussion of the foundations for these assumptions and examples of their implementation makes up the rest of this article.

\section{Rich Environments for Active Learning}

\section{Definition of REALs}

We must implement a number of strategies in order successfully to adopt the new assumptions about thinking, learning, instruction, and achievement described above. The adoption of these strategies creates learning environments that we call Rich Environments for Active Learning (REALs). REALs are comprehensive instructional systems that (Dunlap and Grabinger, 1992, 1993; Grabinger and Dunlap, 1994a, 1994b):

- evolve from and are consistent with constructivist philosophies and theories;

- promote study and investigation within authentic (i.e. realistic, meaningful, relevant, complex, and information-rich) contexts;

- encourage the growth of student responsibility, initiative, decision-making, and intentional learning;

- cultivate an atmosphere of knowledge-building learning communities that utilize collaborative learning among students and teachers (Collins, 1995);

- utilize dynamic, interdisciplinary, generative learning activities that promote high-level thinking processes (i.e. analysis, synthesis, problem-solving, experimentation, creativity, and examination of topics from multiple perspectives) to help students integrate new knowledge with old knowledge and thereby create rich and complex knowledge structures; and,

- assess student progress in content and learning-to-learn through realistic tasks and performances.

It is important to note that two of the overall defining characteristics of learning environments are integration and comprehensiveness (Hannafin, 1992). Hannafin 
describes integration as a process of linking new knowledge to old, and modifying and enriching existing knowledge. Integration enhances the depth of learning to increase the number of access points to that information. As we described earlier, learning environments must go beyond general, abstracted learning to include specific learning. Goldman et al state that:

These environments are designed to invite the kinds of thinking that help students develop general skills and attitudes that contribute to effective problem solving, plus acquire specific concepts and principles that allow them to think effectively about particular domains. (p. 1)

Comprehensiveness, the second defining characteristic, carries this notion further. It refers to the importance of placing learning in broad, realistic contexts rather than in decontextualized and compartmentalized contexts. REAL learning strategies, then, guide and mediate an individual's learning, and support the learner's decision-making (Hannafin, 1992). Themes are used to help organize learning around interdisciplinary contexts that focus on problem-solving or projects that link concepts and knowledge to focused activities within the environment (Hannafin, 1992).

What a REAL is not

Because the phrase learning environment is broadly and carelessly used in educational literature to describe everything from schools to classrooms to computer microworlds to learning activities to air conditioning and furniture, we shall try to clarify what a REAL is not before examining the attributes in more detail. We attempt to make the case that a REAL is a more accurate description of what people generally mean when they use the term learning environment.

First, a REAL is not a delivery technology like video, CD-ROM, or audio tapes. Clark (1994) defines delivery technologies as those that draw on resources and media to deliver instruction, and affect the cost and access of instruction. Media technologies can be integral components of REALs and, in fact, usually are. However, a REAL is not limited to any specific media, but instead is an assortment of methods and ideas that help create an environment that promotes and encourages active learning. Clark's point is important from a research standpoint because instructional methods are often confounded with media in research, and he argues strongly and convincingly that it is instructional methods, not media, that influence learning. He contends that any necessary teaching method can usually be designed in more than one medium. Although there are varying degrees of acceptance and disagreement with Clark's point of view (for example, Jonassen, 1994b; Kozma, 1994), a REAL is a set of instructional methods designed on the assumptions that media are tools for students and teachers to use, and that the learning that occurs within the environment is founded on the activities and processes that encourage thinking and reasoning, not the media that deliver information.

Second, do not confuse REALs with computer-based microworlds or learner-support environments (Allinson and Hammond, 1990). Computer-based microworlds are computer programs that are designed to apply constructivist theories. Examples include case-based applications, simulations, intentional learning environments, and some hypermedia resources. Developers of microworlds often refer to their programs as learning environments because they often attempt to simulate, on a smaller simplified 
scale, realistic environments. However, we contend that this limits the concept of learning environment. Learning environments, and especially REALs, are much more comprehensive and holistic than individual computer applications. Although some computer-based applications use constructivist ideas quite admirably - see especially the Strategic Teaching Framework (Duffy, 1992; Duffy, in press), and the 'Transfusion Medicine Modules (Ambruso and The Transfusion Medicine Group, 1994) - they are not learning environments in the sense that REALs are. To create REALs, teachers must involve their students, parents, administrators, and colleagues in planning and implementing strategies that encourage student responsibility, active knowledge construction, and generative learning activities on a large scale and in a variety of methods and forms. Microworlds may play a role in a REAL through the delivery of information, practice, finding and presenting information, stimulation of high-level thought processes, promotion of collaboration, or exploration; but REALs involve many more activities and demand much more flexibility than can probably ever be contained in a single computer program. A REAL is, then, a learning community that 'includes the content taught, the pedagogical methods employed, the sequencing of learning activities, and the sociology of learning' (Collins et al, 1991, p. 6).

Finally, a REAL is not the physical attributes of the classroom. It is not about air conditioning, desks, lighting, or ergonomics. While these environmental factors are critical in creating a smooth-operating learning environment, they are not included in our definition or REALs (for information about this topic, see Gayeski, 1995).

\section{Foundation of REALs}

REALs (i.e. constructivist learning environments, information-rich learning environments, interactive-learning environments, or knowledge-building learning communities) are not new to education. We can go back to Socrates and see that he used problems and questions to guide students to analyse and think about their environments (Coltrane, 1993). Rousseau prescribed using direct experience (Farnham-Diggory, 1992). In the early 1900s, John Dewey (1910) proposed student-directed reforms and experiential learning. Bruner (1961) advocated discovery or inquiry learning around realistic problems. The notion that students should learn through practice, application, and apprenticeship has been with us for centuries. It was not until the industrial age, when we needed places to store children until old enough to work on assembly lines, that we began trying to mass produce replicable results. Yet the last five to ten years have seen renewed emphasis on reforming schools and teaching practices to replace our educational production lines with classrooms that teach people to think and solve problems. This current effort at renewal revolves around a set of ideas and theories referred to as constructivism.

\section{Characteristics of constructivism}

The class of theories that guides the development of REALs is called constructivist theories (Clement, 1982; Bransford and Vye, 1989; Minstrell, 1989; Resnick and Klopfer, 1989; Schoenfeld, 1989; Bednar et al, 1991; Duffy and Bednar, 1991; Perkins, 1991; Scardamalia and Bereiter, 1991; Spiro et al, 1991). Fundamentally, constructivism asserts that we learn through a continual process of building, interpreting, and modifying our own representations of reality based upon our experiences with reality (Jonassen, 1994c). 
Wheatley (1992) elaborates on the importance of this idea not just in learning but also in the innovation and improvement of society:

Learning (innovation) is fostered by information gathered from new connections; from insights gained by journeys into other disciplines or places; from active, collegial networks and fluid, open boundaries. Learning (innovation) arises from ongoing circles of exchange where information is not just accumulated or stored, but created. Knowledge is generated anew from connections that weren't there before. When this information self-organizes, learning (innovation) occurs, the progeny of information-rich, ambiguous environments. (p. 113)

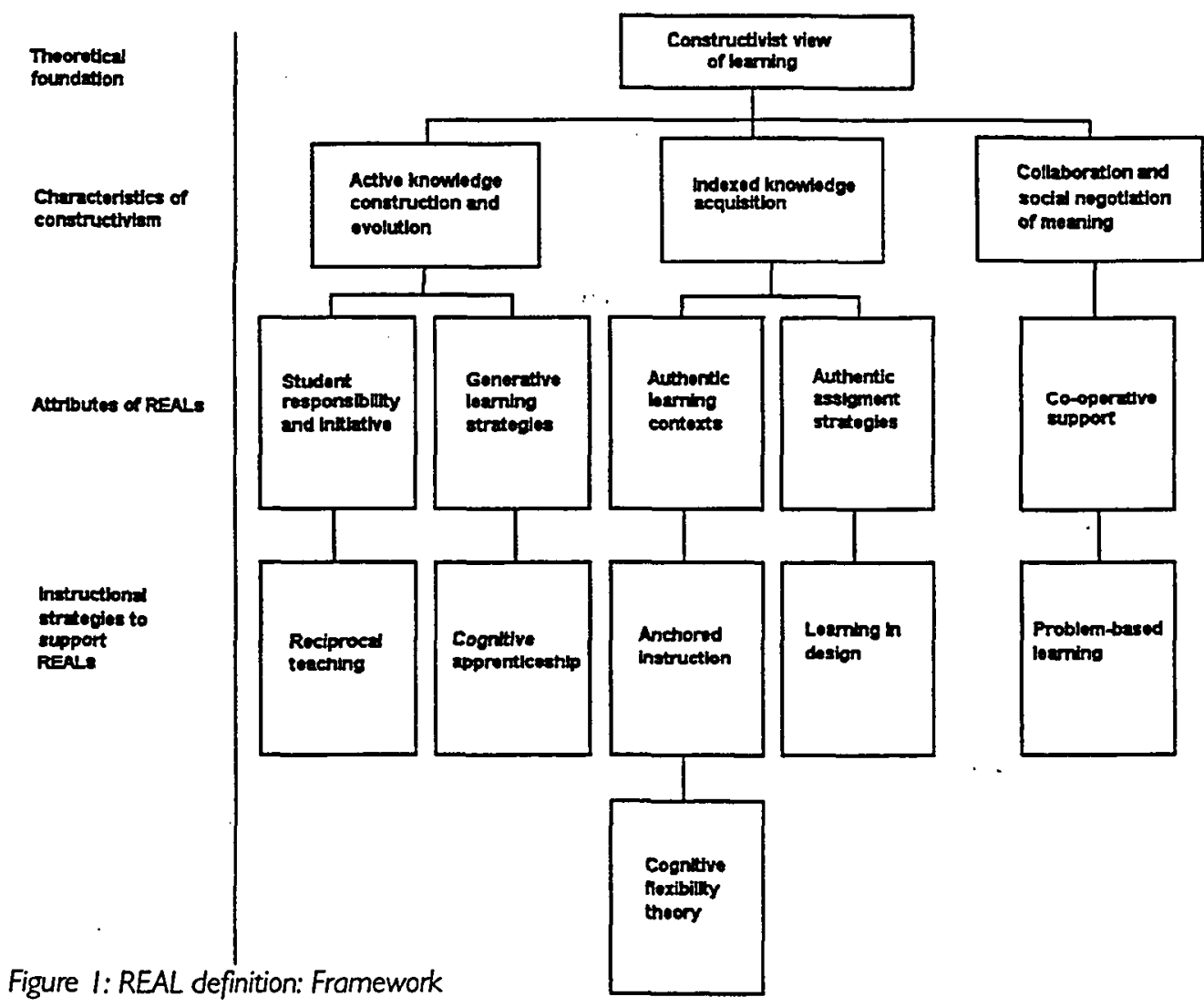

To develop learning environments that encourage the type of learning described by Jonassen, Wheatley, and others, REALs reflect the theories and philosophies of constructivism. In fact, the three main characteristics of the constructivist view of learning govern our design of REALs (see Figure 1). The first characteristic of constructivism is the notion that knowledge is not a product to be accumulated but an active and evolving process in which the learner attempts to make sense out of the world (Gurney, 1989). Brown et al (1989) illustrate this idea:

A concept, for example, will continually evolve with each new occasion of use, because new situations, negotiations, and activities inevitably recast it in a new, more densely textured form. So a concept, like the meaning of a word, is always under construction. (p. 33) 
The second characteristic is the notion that people conditionalize their knowledge in personal ways (Gurney, 1989). That is, they acquire knowledge in forms that enable them to use that knowledge later. Bransford et al (1990) state that:

[. . . ] there are large differences between knowing something and spontaneously thinking to do it or use it when one is engaged in an actual problem-solving situation. (p. 122)

Knowledge, then, is 'indexed' to the contexts in which we encounter it. We are unlikely to use knowledge that is decontextualized because we can see no relevance - no contextual cues cause us to remember that knowledge because it was taught without cues. A person who indexes and conditionalizes knowledge knows when to apply that knowledge. A person who learns in a decontextualized way often is not aware that he or she has the applicable knowledge to solve a problem. In other words, knowledge acquired is inert.

Students must acquire concepts and theories in ways that help them use the information later on, and appreciate the value of that information. Brown et al $(1989$, p. 36$)$ describe this process as indexicalizing knowledge. They mean that rich involvement in realistic and relevant problem-solving allows learners to develop many broad and deep indexicalized representations that enable them to apply knowledge more spontaneously to new situations because they can compare a known and relevant situation with a new situation. The more links there are across related knowledge structures, the more likely students are to apply that knowledge. The more closely the learning context resembles the actual context, the better people will perform. Tulving and Thompson (1973) refer to this as 'encoding specificity,' which holds that successful retrieval of information is enhanced when cues relevant to later retrieval of that information are encoded along with the material learned. It is important to note that constructivists contend that these rich links cannot be developed in decontextualized learning activities; rather, learning must be placed in realistic contexts that provide cognitive conflict or puzzlement, and determine the organization and nature of what is learned (Savery and Duffy, 1994).

White (see Robertson, 1990) theorizes that there are two kinds of links that need to be developed while learning: internal and external. Internal associations are connections among the criterial attributes of a principle. Internal associations reflect the learner's understanding of the concept. External associations refer to connections between the principle and everyday experiences or context, and indicate the 'usability' of a concept. Learning to solve problems requires both kinds of links. Our schools are good at building the internal links, but poor at providing the external links.

The third major characteristic of constructivism is the importance of collaboration and social negotiation of meaning. Learning happens within a social context. Conceptual growth comes from sharing our perspectives and testing our ideas with others, modifying our internal representations in response to that process of negotiation (Bednar et al, 1991). Common understandings and shared meanings are developed through interaction among peers and teachers. This is the cultural aspect of knowledge.

The activities of a domain are framed by its culture. Their meaning and purpose are socially constructed through negotiations among present and past members. Activities thus cohere in a way that is, in theory if not always in practice, accessible to members who move within the social framework. These coherent, meaningful, and purposeful 
activities are authentic, according to the definition of the term we use here. (Brown et al, 1989, p. 34)

This social aspect of constructivism is important on an individual level as well as cultural level, for collaborative interactions allow us to test the viability of our understandings, theories, and conjectures (Savery and Duffy, 1994).

REALs embody the characteristics of constructivism, but how? What are the critical attributes of REALs that support a constructivist view of learning? The next section of this article discusses each of the criterial attributes of a REAL:
A. Student responsibility and initiative.
B. Generative learning activities.
C. Authentic learning contexts.
D. Authentic assessment strategies.
E. Co-operative support.

We will illustrate each attribute with examples of functioning REALs utilizing the strategies of reciprocal teaching, cognitive apprenticeship, anchored instruction, cognitive flexibility theory, learning in design, and problem-based learning (PBL).

\section{The main attributes of REALs}

\section{A. Student responsibility and initiative}

The first attribute of REALs is that they are student-centred. Student-centred learning environments place a major emphasis on developing intentional learning and life-long learning skills. These skills include the abilities to construct higher-order questions to guide learning, reflect on consequences and implications of actions, and monitor and modify personal cognitive activity. This attribute is critical because students cannot actively construct and evolve their knowledge structures without taking responsibility and initiative for their learning.

Intentional learning

Scardamalia and her colleagues (1989) noticed that passive or immature learners have certain characteristics that prevent them from becoming skilful problem solvers. First, immature learners tend to organize their mental activities around topics rather than goals, promoting decontextualization and the inability to see the relevance of the learning activity to their lives. Second, they tend to focus on surface features, and do not examine a topic in depth. Third, they tend to work until a task is finished. They do not take time to examine the quality of their work, nor do they take the time to consider revisions to their finished product or to the strategies utilized to complete the task. When the task is finished, they forget whatever learning took place during their work on the task. Finally, they think of learning in an additive fashion rather than transforming and enriching their existing knowledge structures.

These characteristics are, in essence, the product of the conventional kind of schooling that we described earlier. These behaviours prevent students from transferring their 
knowledge to new problems because they have learned content and strategies in a decontextualized context. Palincsar (1990) states that:

To achieve transfer it is necessary to attend to the context in which instruction and practice occur; transfer is likely to occur to the extent that there are common elements between the situation in which the children are learning this tactic and the situations in which such a tactic would be useful. (p. 37)

Palincsar, Scardamalia, and Bereiter are leading proponents of the conviction that students must be taught to take more responsibility for their own learning to enhance the likelihood of transfer. They refer to this concept as intentional learning, or 'those cognitive processes that have learning as a goal rather than an accidental outcome' (Bereiter and Scardamalia, 1989, p. 363). Palincsar and Klenk (1992) state that 'intentional learning, in contrast to incidental learning, is an achievement resulting from the learner's purposeful, effortful, self-regulated, and active engagement'. To be intentional learners, students must learn to learn as well as accrue knowledge. Teaching, too, takes on a revised role, for to teach for intentional learning means to cultivate those general abilities that facilitate life-long learning (Palincsar, 1990). The main skills involved in teaching students to be more intentional are questioning, self-reflection, and metacognition, 'or the awareness and ability to monitor and control one's activity as a learner' (Brown et al, 1983, p. 212).

Questioning

Scardamalia and Bereiter (1991) believe that one of the first steps in developing intentional learners is to help students take more executive control over what they decide to learn through the development of higher-order questioning skills. They point out that in a typical classroom, teachers ask all the questions. Therefore, teachers are the ones engaged in the question generation process, which involves important high-level thinking skills and executive control decisions - the skills students need to develop actively to construct and evolve their knowledge structures. The students are not given an opportunity to ask questions and, therefore, do not learn to perform the analysis activities related to question generation. Research by Scardamalia and Bereiter (1991) indicates that students can learn to ask questions to guide their knowledge-building, thus assuming a 'higher level of agency' and more ownership for their learning. In a student-centred REAL, students are given more executive control over their learning to enable them to take more ownership, to find more relevance and authenticity, and to learn life-long learning skills.

\section{Self-Reflection}

A second skill in intentional learning is self-reflection. 'Self-reflection implies observing and putting an interpretation on one's own actions, for instance considering one's own intentions and motives as objects of thought' (Von Wright, 1992, p. 61). Von Wright writes that self-reflection involves the abstraction of meaning and is an interpretative process aimed at the understanding of reality. To understand the world in different ways involves modifying our conceptions of the world and our place in the world. It involves thinking about reality in alternative ways. Von Wright goes on to describe two levels of reflection. One level of reflection is the ability to think about consequences and implications of actions. A second level of reflection is the ability to think about oneself as 
an intentional subject of one's own actions and to consider the consequences and efficacy of those actions. This involves the ability to look at oneself in an objective way, and to consider ways of changing future actions to improve performance. The second level of reflection also involves metacognitive learning skills.

Metacognitive skills

'Metacognitive skills refer to the steps that people take to regulate and modify the progress of their cognitive activity: to learn such skills is to acquire procedures which regulate cognitive processes' (Von Wright, 1992, p. 64). Metacognitive skills include taking conscious control of learning, planning and selecting strategies, monitoring the progress of learning, correcting errors, analysing the effectiveness of learning strategies, and changing learning behaviours and strategies when necessary (Ridley et al, 1992). These abilities interact with developmental maturation and domain expertise. Immature learners have not acquired the ability to regulate or modify their cognitive activity; they may have learned a single strategy, such as memorization, and default to that one strategy in all situations.

Studies show that the use of metacognitive strategies can improve learning skills, and that the independent use of these metacognitive strategies can be gradually developed in people (Brown, 1978; Biggs, 1985; Weinstein et al, 1988). Blakely and Spence (1990) describe several basic instructional strategies that can be incorporated into classroom activities to help students develop metacognitive behaviours:

- Students should be asked to identify consciously what they 'know' as opposed to what they 'do not know'.

- Students should keep journals or logs in which they reflect upon their learning processes, noting what works and what does not.

- Students should manage their own time and resources, including estimating time required to complete tasks and activities, organizing materials and resources, and scheduling the procedures necessary to complete an activity.

- Students must participate in guided self-evaluation using individual conferences and checklists to help them focus on the thinking process.

REAL strategy: reciprocal teaching

One of the manifestations of a REAL that emphasizes the development of intentional learning skills described above is reciprocal teaching. The context of reciprocal teaching is social, interactive, and holistic. Palincsar and Klenk (1992) used reciprocal teaching with at-risk first-grade students to develop reading skills. Palincsar and Klenk (1992) describe reciprocal teaching as:

[. . .] an instructional procedure that takes place in a collaborative learning group and features guided practice in the flexible application of four concrete strategies to the task of text comprehension: questioning, summarizing, clarifying, and predicting. The teacher and group of students take turns leading discussions regarding the content of the text they are jointly attempting to understand. (p. 213)

These strategies are the kinds of intentional learning strategies that encourage selfregulation and self-monitoring behaviours. 
The relationship of reciprocal teaching to REALs is founded on three theoretical principles, consistent with the characteristics of constructivism described previously, based on the work of Vygotsky (1978) as described by Palincsar and Klenk (1992). The first principle states that the higher cognitive processes originate from social interactions. The second principle is Vygotsky's Zone of Proximal Development (ZPD). Vygotsky described the ZPD as:

[. . .] the distance between the actual developmental level as determined by independent problem-solving, and the level of potential development as determined through problemsolving under adult guidance or in collaboration with more capable peers. (p. 86)

Reciprocal teaching is designed to provide a ZPD in which students, with the help of teachers and peers, take on greater responsibility for learning activities. Finally, Vygotsky's third principle advocates that learning take place in a contextualized, holistic activity that has relevance for the learners.

How, then, does reciprocal teaching work? The process begins with a text that a class reads silently, orally, or along with the teacher depending on the skill level of the students. Following each segment, a dialogue leader (students take turns) asks questions that deal with content or 'wonderment' issues. The questions often stimulate further inquiry. The other students respond to the questions, raise their own questions, and, in cases of disagreement or confusion, re-read the text. The discussion leader is responsible for summarizing and synthesizing the reading and discussion, and clarifying the purpose of the reading. The leader also generates and solicits predictions about the upcoming text to prepare for meaningful reading of the next segment. The teacher must model the appropriate behaviour and provide scaffolding to sustain the discussion. (The preceding description is taken from Palincsar and Klenk, 1992.) The students, then, are involved in the higher-level thinking and decision-making activities that usually fall within the realm of the teacher. With the help of the teacher, students share a ZPD where they can learn the questioning, summarizing, clarifying and predicting activities so integral to metacognitive awareness.

Finally, why does reciprocal teaching work? Collins et al (1991) posit the following reasons for its success (and, in a broader view, for the success of REALs):

- The reciprocal teaching model engages students in activities that help them form a new conceptual model of the task of reading. They see reading as a process that involves reflection and prediction rather than just the recitation of words. They learn to make what they are reading relevant to their needs and to monitor their progress and strive for clarification.

- The teacher and student share a problem context while the teacher models expert strategies that the students learn to use independently.

- Scaffolding is crucial in the success of reciprocal teaching. 'Most importantly, it, decomposes the task as necessary for the students to carry it out, thereby helping them to see how, in detail, to go about it' (Collins, et al, 1991, p. 11).

- Finally, students learn the self-monitoring activities and thinking processes involved in critiquing and improving their work. 


\section{B. Generative learning activities}

The second requirement of REALs is that students engage in generative learning activities. People who learn through active involvement and use tools build an 'increasingly rich implicit understanding of the world' (Brown et al, 1989, p. 33). Generative learning requires that students 'engage in argumentation and reflection as they try to use and then refine their existing knowledge as they attempt to make sense of alternate points of view' (CTGV, 1993b, p. 16). Studies indicate that knowledge is more likely to be active and used when acquired in a problem-solving mode rather than in a factual-knowledge mode (Adams et al, 1988; Lockhart et al, 1988). The concept of generative learning is an extension of the constructivist characteristic of actively constructing knowledge; students cannot construct or evolve their own learning without generating something through active involvement.

Generative learning requires a shift in the traditional roles of students and instructors. Students become investigators, seekers, and problem solvers. Teachers become facilitators and guides, rather than presenters of knowledge. For example, rather than simply learning what objectives and goals are, students in a teacher-education class generate lesson plans and objectives and then manipulate and revise them to solve new teaching problems. Ideally, they test their objectives, goals, and strategies in actual practice-teaching situations. In generative learning, students apply the information they learn. Generative learning activities require students to take static information and generate fluid, flexible, usable knowledge. Generative learning, then, means that students are involved deeply and constantly with creating solutions to authentic problems via the development and completion of projects. A REAL strategy that relies heavily on projects is cognitive apprenticeship.

REAL strategy: cognitive apprenticeship

Cognitive apprenticeship is modelled after the traditional apprenticeship way of learning arts and crafts. It incorporates elements of traditional apprenticeship and modern schooling. In traditional apprenticeship, the processes of an activity are visible and involve learning a physical and outwardly observable activity (Collins et al, 1991). The expert shows an apprentice how to perform a task, then watches and coaches as the apprentice practises portions of the task, and finally turns over more and more responsibility to the apprentice until the apprentice can perform the task alone (Collins et $a l, 1991)$. Traditional apprenticeship deals with processes that are easily visible because they involve skills and produce visible products.

The goal of cognitive apprenticeship is to make processes that are normally invisible visible. In schooling, the process of thinking is usually invisible to both students and teachers. For example, the practices of problem-solving, reading comprehension, and computation are not visible processes (Collins et al, 1991). Brown et al (1989) point out that the term cognitive apprenticeship emphasizes that apprenticeship techniques can reach beyond observable physical skills to the kinds of cognitive skills associated with learning in schools. In a cognitive apprenticeship environment, the teacher attempts to make visible the thinking processes involved in performing a cognitive task. The teacher first models how to perform a cognitive task by thinking aloud. Then the teacher watches, coaches, and provides scaffolding as the students practise portions of the task. Finally, he or she turns over more and more responsibility to students, and fades coaching and 
scaffolding until they can perform the task alone. 'Cognitive apprenticeship supports learning in a domain by enabling students to acquire, develop, and use cognitive tools in an authentic domain activity' (Brown et al, 1989, p. 39).

The differences between traditional and cognitive apprenticeship (Collins et al, 1991) are important because they indicate where the effort must be placed on the instructional design of learning activities. First, in traditional apprenticeship the task is easily observable. In cognitive apprenticeship, the thinking processes must be deliberately brought into the open by the teacher, and the teacher must help students learn to bring their thinking into the open. Second, in traditional apprenticeship, the tasks come from work, and learning is situated in the workplace. In cognitive apprenticeship, the challenge is to situate the abstract goals of school curriculum in contexts that make sense to students. Third, in traditional apprenticeship, the skills learned are inherent in the task. In schooling, students learn skills that are supposed to transfer to different tasks. In cognitive apprenticeship, the challenge is to present a range of tasks to encourage reflection and to identify common transferable elements across tasks. The goal is to help students generalize and transfer their learning through conditionalized and indexed knowledge (related to the second characteristic of constructivism).

Cognitive apprenticeship and generative learning are closely linked because the process of making cognitive processes visible means that students must create or generate things that represent those processes. Teachers must create work and tasks that represent the process of solving a problem, writing, or computation in addition to products. To examine the development of student thinking, an English teacher may ask for questions, themes, concept maps, and outlines before students begin writing. Mathematics teachers are often notorious for telling students: 'I want to see your work, not just the answer,' so they can look for errors in the thinking process.

Generative learning is one of the simplest features of a REAL. It simply demands that students produce something of value. It is probably the most exciting part of a REAL because students work on projects and tasks that are relevant to them and to their peers. It keeps students busy and happy - or active - while helping them construct and evolve their knowledge structures.

\section{Authentic learning contexts}

The third attribute of REALs is that learning takes place within an authentic context. An authentic task, activity, or goal provide learning experiences as realistic as possible, taking into consideration the age and maturation level of the students and environmental constraints such as safety and resource availability.

An authentic context incorporates as much fidelity as possible to what students will encounter outside school in terms of tools, complexity, cognitive functioning, and interactions with people (Williams and Dodge, 1992). Therefore, creating an authentic learning context requires more than just presenting students with realistic problems or situations - it also means that students must address the problems or situations realistically as well (Honebein et al, 1993).

Authenticity is important to REALs for three reasons. First, realistic problems hold more relevance to students' needs and experiences because they can relate what they are 
learning to problems and goals that they see every day. Therefore, it encourages students to take ownership of the situation and their own learning. Second, because the situations students encounter during learning are authentic and reflect the true nature of problems in the real world, it develops deeper and richer (indexicalized and conditioned) knowledge structures, leading to a higher likelihood of transfer to novel situations. Finally, because complex problems require a team approach that provides natural opportunities for learners to test and refine their ideas and to help each other understand the content, it encourages collaboration and negotiation.

REAL strategy: anchored instruction

One of the ways to create authentic instruction in a REAL is to anchor that instruction in a realistic event, problem, or theme (CTGV, 1990, 1992a, 1992b, 1993a, 1993d). Anchored instruction is fixed within a real-world event that is appealing and meaningful to students (Bransford et al, 1990) and involves complex contexts that require students to solve interconnected sub-problems. Because students are encouraged to work together to solve these complex problems, they are exposed to multiple perspectives in an environment that gives them an opportunity to test out their ideas, solutions, and processes (CTGV, 1992b).

At the heart of the model is an emphasis on the importance of creating an anchor or focus to generate interest, and to enable students to identify and solve problems and pay attention to their own perception and comprehension of these problems' (Bransford et al, 1990, p. 123).

In anchored learning situations, students develop component skills and objectives in the context of meaningful, realistic problems and problem-solving activities. These complex contexts are called 'macrocontexts' (Williams and Dodge, 1992, p. 373). Addressing a key characteristic of constructivism - indexed knowledge acquisition - the primary goal of anchored instruction (and REALs) is to overcome the problem of inert knowledge. For example, students in an instructional design and development class work in teams with actual clients to develop instruction that will be delivered to another group of students. They must define the problem, identify resources, set priorities, and explore alternative solutions with the same skills and abilities that are required during realistic, outside-theclassroom problem-solving and decision-making activities. This is in direct contrast to the way students develop component skills and objectives in a more conventional classroom environment by working simplified, compartmentalized, and decontextualized problems. Simply stated, it is the difference between providing meaningful, authentic learning activities and 'I'm never going to use this' activities.

Anchored instruction shares many features of programmes that are case-based and problem-based (Barrows, 1985; Spiro et al, 1991; Williams and Dodge, 1992). The idea is to let learners experience the intellectual changes that experts feel when modifying their own understandings from working with realistic situations (CTGV, 1992b).

Effective anchors are intrinsically interesting, fostering ownership, and helping students notice the features of problem situations that make particular actions relevant (Bransford et al, 1990). The CTGV (1991) uses the following design principles when creating anchored instruction. First, they use a video-based presentation format because of the dramatic power of the medium and because of the use of multiple modalities, realistic 
imagery, and omnipresence in our culture. Second they present a problem using actors and a narrative format for interest. Third, the problem solution requires a generative learning format in which students must identify pertinent information in the fourth feature, embedded data design. Fifth, the problem is complex, with the possibility of multiple solutions, and requires a team approach. Sixth, they use pairs of similar problems in different contexts to enrich the indexicalization of knowledge structures. Finally, they attempt to draw links across the curriculum to enhance the relevance of the problem.

One of the CTGV's projects in anchored instruction is the Jasper Woodbury series (CTGV, 1992b). Jasper is a video-based series designed to promote problem-posing, problem-solving, reasoning, and effective communication. Each of Jasper's adventures is a 15- to 20-minute story in which the characters encounter a problem that the students in the classroom must solve before they are allowed to see how the movie characters solved the problem. The Jasper series helps students learn to break a problem into parts, generate sub-goals, find and identify relevant information, generate and test hypotheses, and co-operate with others.

REAL strategy: cognitive flexibility theory

Cognitive Flexibility Theory (CFT) also addresses the need for authentic learning contexts in order to help learners develop conditionalized and indexicalized knowledge structures (Spiro et al, 1991; Jacobson and Spiro, 1992).

Essentially, the theory states that cognitive flexibility is needed in order to construct an ensemble of conceptual and case representations necessary to understand a particular problem-solving situation. The idea is that we cannot be said to have a full understanding of a domain unless we have the opportunity to see different case representations (Borsook and Higginbotham-Wheat, 1992, p. 63).

CFT attempts to teach content in ill-structured domains, that is, in domains where the knowledge-base is so vast and complex that multiple solutions to problems are possible and likely. There are no clear-cut answers in ill-structured domains, so simple algorithms often fail. Ill-structured domains include law, medicine, and education. So, CFT emphasizes the following instructional strategies to help learners develop rich and deep knowledge structures (Jacobson, 1994):

- CFT uses several cases and rich examples in their full complexity. One of the tenets of CFT is to avoid over-simplifying knowledge and examples because this leads to future misunderstandings that are difficult to change.

- CFT uses multiple forms of knowledge representation, providing examples in several kinds of media. CFT encourages students to look at knowledge in several ways and from several perspectives.

- CFT links abstract concepts to case examples and brings out the generalizable concepts and strategies applicable to other problems or cases.

- To avoid the mistakes of over-simplification, CFT presents a number of examples to make apparent, rather than hide, the variability of concepts and themes within the domain. 
Although authentic learning contexts help students to develop knowledge that can be transferred and applied to new problems and situations, the fact that students are engaged in authentic activities creates some unique assessment problems. These issues will be examined next.

\section{Authentic assessment strategies}

Going hand in hand with the need to develop authentic learning contexts, the fourth REAL attribute is the use of authentic assessment strategies to evaluate student performance. Conventional schooling relies on standardized and paper/pencil tests to measure the quantity of knowledge that students have accrued. But traditional tests, written reports, and grading schemes are inappropriate measures (Frederiksen and Collins, 1989), time-consuming to administer and score (Williams and Dodge, 1992), and poor indicators of how students will perform in actual problem-solving conditions. Williams and Dodge also state that students are often assessed on skills different from ones that are taught, and experience problem-solving assessments that tend to be subjective. Testing and assessment must recognize the importance of the organization of the knowledge-base and its connectedness to contexts.

Wiggins (1989) contrasts authentic tests, which he describes as contextualized, complex intellectual challenges against multiple-choice measures that he describes as fragmented and static. According to Wiggins, authentic tests include the following criteria:

- The intellectual design features of tests and evaluation tasks must emphasize realistic complexity, stress depth more than breadth, include ill-structured tasks or problems, and require students to contextualize content knowledge.

- Standards of grading and scoring features should include complex multi-faceted criteria that can be specified and that are reliable across multiple scorers. What constitutes a high level of performance should be explainable to students and teachers before they take the test. Teachers often claim that criteria are subjective, but this is seldom the case; most criteria can be described with some thoughtful effort.

- Tests and evaluations must be diverse, and must recognize the existence of multiple kinds of intelligences. In terms of fairness and equity, evaluations and assessments should allow students to use their strengths within areas where their interests lie.

REAL example: learning in design

Carver et al (1992) elaborate on this theme by proposing an extensive list of behaviours needed by students in a REAL. In their particular manifestation of a REAL, they consider the classroom a design community in which students design instruction for other students, documentaries for local media, and other exhibits for the community. Their program has the same goals of high-level thinking, reflection, and transfer as the other REAL strategies described:

The instructional virtues of these design experiences include the opportunity to develop and coordinate a variety of complex mental skills, such as decomposing a topic into subtopics, gathering data from a variety of sources, organizing diverse and often contradictory information, formulating a point of view, translating ideas into a presentation targeted at a particular audience, evaluating the design, and making revisions based on the evaluations. (Carver et al, 1992, p. 386) 
Again, there are several parallels with the other examples that we have discussed. Their REAL focuses on complex mental skills; analysing, comparing, and manipulating information; working on authentic, community-based tasks; and working with others.

To evaluate fairly students working in this environment, teachers need a clear specification of the skills students need for design tasks and prescriptions for how teachers can effectively support those skills (see also Agnew et al, 1992). Specification of skills and prescriptions of support are two parts of assessment that must be linked for fair assessment. If a skill cannot be supported by the teacher or some kind of scaffolding technique, then it cannot be fairly evaluated. It may, in fact, be outside the ZPD (Zone of Proximal Development) and beyond the current capability of the student. One of the teacher's jobs in a REAL is to specify skills and performances that can be supported so the student can grow in ability. Carver et al (1992) break the important behaviours for their environment into:

- project-management skills, including creating a timeline, allocating resources, and assigning team roles;

- research skills, including determining the nature of the problem, posing questions, searching for information, developing new information, and analysing and interpreting information;

- organization and representation skills, including choosing the organization and structure of information, developing representations (text, audio, and graphics), arranging structure and sequence; and juggling constraints;

- presentation skills, including transferring their design into media and arousing and maintaining audience interest; and

- reflection skills, including evaluating the process and revising the design.

Their criteria work for their learning environment. Other models may need to revise some of the specifics, though the five main categories provide an excellent starting place in specifying skills targeted for assessment in authentic assessments. Goldman, Pellegrino, and Bransford's (1994) discussion of assessment in the CTGV Jasper series suggests the following assessment areas: assessment of complex mathematical problem-solving (mathematics is the content domain of Jasper), measures of group problem-solving performance, assessment of extensions into other areas of the content area, and assessment of cross-curricular extensions. Although conducting an assessment for a REAL is more work than conventional assessment, it is also an integral part of the learning process rather than a periodic quantifiable measure. Authentic assessment provides feedback and information that is useful for planning future learning activities.

Assessment in REALs means that we have to consider more varied techniques. Neuman (1993), in her work with the Perseus hypermedia program, suggests several alternatives. First, she suggests that teachers use more observations including evaluator observations of performance processes, think-alouds by students, and automatic transaction monitoring. Second, she suggests using interviews of students, instructors, and staff using both questionnaires and focus groups. Finally, she suggests using document and product analysis including assignments, syllabi, essays, journals, paths, reports, documentation, and presentations. 


\section{E. Co-operative support}

The fifth and final characteristic of REALs, and one that is an important feature of almost all the other REAL strategies described above, acknowledges the transactional nature of knowledge and suggests that a shift be made to focus on social practice, meaning, and patterns (Roth, 1990). 'All cooperative learning methods share the idea that students work together to learn and are responsible for one another's learning as well as their own' (Slavin, 1991, p. 73). Working in peer groups helps students refine their knowledge through argumentation, structured controversy, and the sharing and testing of ideas and perspectives. Additionally, students are more willing to take on the extra risk required to tackle complex, ill-structured, authentic problems when they have the support of others in the co-operative group. Co-operative learning and problem-solving groups also address students' needs for scaffolding during unfamiliar learning and problemsolving activities; therefore, with the support of others in the group, students are more likely to achieve goals they may not have been able to meet on their own.

Constructivists argue that co-operative learning and problem-solving groups facilitate generative learning. Some of the generative activities that students engage in co-operative groups include (Brown et al, 1989):

- Collective problem-solving. Groups give rise synergistically to insights and solutions that would not come about individually.

- Displaying multiple roles. Group participation means that the members must understand many different roles. They also may play different roles within the group to gain additional insights.

- Confronting ineffective strategies and misconceptions. Teachers do not have enough time to hear what students are thinking or how they are thinking. Groups draw out, confront, and discuss both misconceptions and ineffective strategies.

- Providing collaborative work skills. Students learn to work together in a give-and-take interaction rather than just dividing the workload.

Research indicates that co-operative learning, when implemented properly, is highly successful. Slavin (1991) provides the following four summary statements regarding research findings in co-operative learning:

- Successful co-operative-learning strategies always incorporate the two key elements of group goals and individual accountability.

- When both group goals and individual accountability are used, achievement effects are consistently positive. Slavin's review found that 37 of 44 experimental/control comparisons of at least four weeks' duration found significantly positive effects for cooperative group methods with none favouring traditional methods.

- Positive achievement effects are present to about the same degree across all US grade levels (2-12), in all major subjects, and in urban, rural, and suburban schools. Effects are equally positive for high, average, and low achievers.

- Positive effects of co-operative learning are consistently found on such diverse 
outcomes as self-esteem, inter-group relations, acceptance of academically handicapped students, attitudes toward school, and ability to work co-operatively.

REAL strategy: problem-based leaming

Problem-based learning (PBL) embodies the definition of a rich environment for active learning, and incorporates all attributes previously described. PBL is 'the learning that results from the process of working toward the understanding or resolution of a problem' (Barrows and Tamblyn, 1980, p. 18). PBL found initial acceptance in the medical field, and has grown to become a major learning system for a number of medical, law, and business schools. It is also being adapted for use in secondary schools and corporate training environments (Dunlap, 1995). PBL reflects the REAL attribute that knowledge is constructed rather than received, for it is based on the assumption that knowledge arises from work with an authentic problem (Coltrane, 1993). Benor (1984) states that:

Problem-based learning in the context of medical education means self-directed study by of [sic] learners who seek out information pertinent to either a real-life or a simulated problem. The students have to understand the problem to the extent that its constituents can be identified and defined. The learners have then to collect, integrate, synthesize and apply this information to the given problem, using strategies that will yield a solution. (p. 49)

How does PBL work? Savery and Duffy (1994) describe four characteristics of PBL.

First, PBL environments include the learning goals of realistic problem-solving behaviour, self-directed learning, content knowledge acquisition, and the development of metacognitive skills.

Second, Savery and Duffy state that PBLs are based on problems that are generated because they raise relevant concepts and principles that are authentic. Problems must be authentic because it is difficult to create artificial problems that maintain the complexity and dimensions of actual problems. Recall that we encountered the need for complexity in the REAL strategies of anchored instruction and cognitive flexibility theory. Realistic problems also have a motivational effect. They tend to engage learners more because they want to know the outcome of the problem. When the learning context is similar to the situation in which the learning is to be applied, learning transfer is more likely to occur. Therefore, we see the continual reference to the necessity for transfer in PBL.

Third, the actual presentation of the problem is a critical component of PBLs. Problems are encountered before any preparation or study has occurred (Barrows, 1980). The problem must be presented in a realistic way that encourages students to adopt and take ownership for the problem (Barrows and Tamblyn, 1980; Savery and Duffy, 1994). Work on the problem begins with activating prior knowledge to enable students to understand the structure of the new information. Learners state what they already know about the problem domain. They use that knowledge to form hypotheses or ideas about potential solutions. We also see this principle emphasized in intentional learning, because students must ask themselves what they know about a subject before creating learning plans. The data must be embedded in the problem presentation (refer back to the example of anchored instruction) but must not highlight the critical factors in the case. Students must 
make their own decisions about what is critical because that is cognitively authentic - it reflects actual job performance (Savery and Duffy, 1994).

Fourth, the facilitator has a crucial role comparable to the roles described in anchored instruction and reciprocal teaching. The facilitator interacts with the students at a metacognitive level, helping them ask the right questions and monitor their own progress. Facilitators avoid expressing opinion, giving information, or leading to a correct answer. Their role is to challenge the students, and help them reflect on what they are learning. (Savery and Duffy, 1994).

Co-operative learning is a critical component of PBL for it is used from the beginning to the end of the problem-solution process. Members of the group listen to the problem presentation together. They analyse the problem's components, recall what they know, hypothesize, consider possible resources, and choose directions to go. They test and help each other. They work together on the solutions and reach consensus on final actions. The entire process from beginning to end is co-operative. Co-operative learning is also used for its motivational factors.

Problem discussion also increases motivation by gaining and maintaining student interest (attention), by relating the learning to student needs or helping students to meet personal goals (relevance), by providing conditions conducive to student success (confidence), and through the motivation provided by that mastery of the task(s) (satisfaction) (Coltrane, 1993, pp. 12-13).

PBL is the epitome of the REAL constructive learning process. Students work with problems in a manner that fosters reasoning and knowledge application appropriate to their levels of learning. In the process of working on the problem and with their peers, students identify areas of learning to guide their own individualized study. The skills and knowledge acquired by this study are applied back to the problem to evaluate the effectiveness of learning and to reinforce learning. The learning that has occurred in work with the problem and in individualized study is summarized and integrated into the student's existing knowledge structure.

\section{Conclusion}

Times have changed. People now need to be able to think flexibly and creatively, solve problems, and make decisions within complex, ill-structured environments. Given these changes, our assumptions on learning and education are out-dated, forcing us to modify our assumptions based on current theoretical views of learning. These new assumptions, supported by the theories and philosophies of constructivism, require different instructional methods, techniques, and strategies than have been conventionally used in classroom settings. Reflecting a constructivist view of learning, REALs provide a way for us to address these new assumptions in order to meet the educational demands of a changing society.

We have looked at each of the five main attributes of REALs that support the goals of constructivism: (1) student responsibility and initiative, (2) generative learning activities, (3) authentic learning contexts, (4) authentic assessment strategies, and (5) co-operative support. Each REAL attribute builds upon and uses the others. None of the attributes are 
mutually exclusive, and no one attribute is more important than another; you cannot implement one feature without incorporating the others to some degree. In effect, the attributes of REALs mirror the comprehensive, integrated, and holistic nature of REALs. The characteristics are symbiotic, with one feature both supporting and needing the others to create a successful rich environment for active learning.

\section{References}

Adams, L., Kasserman, J., Yearwood, A., Perfetto, G., Bransford, J. and Franks, J. (1988), 'The effects of facts versus problem-oriented acquisition', Memory and Cognition, $16,167-75$.

Agnew, P., Kellerman, A., and Meyer, J. (1992), 'Constructing multimedia: solutions for education', paper presented at the 34th Annual International Conference of the Association for the Development of Computer-Based Instructional Systems, Norfolk VA.

Albanese, M.A. and Mitchell, S. (1993), 'Problem-based learning: a review of literature on its outcomes and implementation issues', Academic Medicine, 68 (1), 52-81.

Allinson, L. and Hammond, N. (1990), 'Learning support environments: rationale and evaluation', Computers in Education, 15 (1), 137-43.

Ambruso, D. and The Transfusion Medicine Group. (1994), Transfusion Medicine Modules [computer programs], Denver CO, The Bonfils Blood Center.

American Association for the Advancement of Science (1989), a project 2061 report on literacy goals in science, mathematics, and technology, Washington DC, AAAS.

Barrows, H.S. (1985), How to Design a Problem-based Curriculum for the Preclinical Years, New York, Springer-Verlag.

Barrows, H.S. and Tamblyn, R.M. (1980), Problem-based Learning: An Approach to Medical Education, New York, Springer Publishing Company.

Bednar, A.K., Cunningham, D., Duffy, T.M. and Perry, J.D. (1991), 'Theory into practice: how do we link?' in Anglin, G.J. (ed), Instructional Technology: Past, Present, and Future (pp. 88-101), Englewood CO, Libraries Unlimited.

Benor, D.E. (1984), 'An alternative, non-Brunerian approach to problem-based learning' in Schmidt, H.G. and d. Volder, M.L. (eds), Tutorials in Problem-based Learning: New Directions in Training for the Health Professions (pp. 48-58), Assen/Maastricht, Van Gor Cum.

Bereiter, C. and Scardamalia, M. (1989), 'Intentional learning as a goal of instruction' in Resnick, L.B. (ed), Knowing, Learning, and Instruction: Essays in Honor of Robert Glaser (pp. 361-92), Hillsdale NJ, Lawrence Erlbaum.

Berryman, S.E. (1991), Designing Effective Learning Environments: Cognitive Apprenticeship Models, ERIC Document 337 689, 1-5.

Biggs, J.B. (1985), 'The role of metalearning in study processes', British Journal of Educational Psychology, 55, 185-212.

Blakey, E. and Spence, S. (1990), Developing Metacognition, ERIC Document 327 218, 1-4. 
Borsook, T.K. and Higginbotham-Wheat, N. (1992), 'The psychology of hypermedia: a conceptual framework for R and D', paper presented at the 1992 National Convention of the Association for Educational Communications and Technology, Washington DC.

Bransford, J.D., Sherwood, R.D., Hasselbring, T.S., Kinzer, C.K. and Williams, S.M. (1990), 'Anchored instruction: why we need it and how technology can help' in Nix, D. and Spiro, R. (eds), Cognition, Education, and Multimedia: Exploring Ideas in High Technology (pp. 115-41), Hillsdale NJ, Lawrence Erlbaum.

Bransford, J. and Vye, N.J. (1989), 'A perspective on cognitive research and its implications for instruction' in Resnick, L. and Klopfer, L.E. (eds), Toward the Thinking Curriculum: Current Cognitive Research (pp. 173-205), Alexandria VA, ASCD.

Bransford, J., Goldman, S.R. and Vye, N.J. (1991), 'Making a difference in peoples' abilities to think: reflections on a decade of work and some hopes for the future' in Okagaki, L. and Sternberg, R.J. (eds), Directors of Development: Influences on Children (pp. 147-80), Hillsdale NJ, Lawrence Erlbaum.

Brown, A.L. (1978), 'Knowing when, where, and how to remember: a problem of metacognition' in Glaser, R. (ed), Advances in Instructional Psychology, Hillsdale NJ, Lawrence Erlbaum.

Brown, A.L., Bransford, J.D., Ferrara, R.A. and Campione, J.C. (1983), 'Learning, remembering, and understanding' in Flavell, J.H. and Markman, E.M. (eds), vol. 3, Handbook of Child Psychology: Cognitive Development (pp. 177-266), New York, Wiley.

Brown, J.S., Collins, A. and Duguid, P. (1989), 'Situated cognition and the culture of learning', Educational Researcher, January-February, 32-42.

Bruner, J.S. (1961), 'The act of discovery', Harvard Educational Review, 21-32.

Butterfield, E. and Nelson, G. (1989), 'Theory and practice of teaching for transfer', Educational Technology Research and Development, 37 (3), 5-38.

Carver, S.M., Leherer, R., Connell, T. and Erickson, J. (1992), 'Learning by hypermedia design: issues of assessment and implementation', Educational Psychologist, 27 (3), 385404.

Clark, R.E. (1994), 'Media will never influence learning', Educational Technology Research and Development, 42 (2), 21-9.

Clark, R.E. and Voogel, A. (1985). 'Transfer of training principles for instructional design', Educational Communication and Technology Journal, 33 (2), 113-25.

Clement, J. (1982). 'Algebra word problem solutions: thought processes underlying a common misconception', Journal of Research in Mathematics Education, 13, 16-30.

CTGV (Cognition and Technology Group at Vanderbilt) (1990), 'Anchored instruction and its relationship to situated cognition', Educational Researcher, 19 (6), 2-10.

CTGV (Cognition and Technology Group at Vanderbilt) (1991), 'Technology and the design of generative learning environments', Educational Technology, 31, 34-40.

CTGV (Cognition and Technology Group at Vanderbilt) (1992a), 'Anchored instruction 
in science and mathematics: theoretical basis, developmental projects, and initial research findings' in Duschl, R.A. and Hamilton, R.J. (eds), Philosophy of Science, Cognitive Psychology, and Educational Theory and Practice (pp. 244-73), New York, SUNY Press.

CTGV (Cognition and Technology Group at Vanderbilt) (1992b), 'The Jasper Series as an example of anchored instruction: theory, program description, and assessment data', Educational Psychologist, 27 (3), 291-315.

CTGV (Cognition and Technology Group at Vanderbilt) (1993a), 'Anchored instruction and situated cognition revisited', Educational Technology, 13 (3), 52-70.

CTGV (Cognition and Technology Group at Vanderbilt) (1993b), 'Designing learning environments that support thinking' in Duffy, T.M, Lowyck, J. and Jonassen, D.H. (eds), Designing Environments for Constructive Learning (pp. 9-36), New York, Springer-Verlag.

CTGV (Cognition and Technology Group at Vanderbilt) (1993c), 'Integrated media: toward a theoretical framework for utilizing their potential', Journal of Special Education Technology, 12 (2), 76-89.

CTGV (Cognition and Technology Group at Vanderbilt) (1993d), 'The Jasper Series: theoretical foundations and data on problem solving and transfer' in Penner, L.A., Batsche, G.M., Knoff H.M. and Nelson, D.L. (eds), The Challenges in Mathematics and Science Education: Psychology's Response (pp. 113-52), Washington DC, American Psychological Association.

Collins, A. (1995), 'Learning communities', presentation at the annual conference for the American Educational Research Association, San Francisco CA, April, 1995.

Collins, A., Brown, J.S. and Holum, A. (1991), 'Cognitive apprenticeship: making thinking visible', American Educator (Winter), 6-11, 38-46.

Coltrane, L. (1993), 'An overview of problem-based learning in medical education' (class paper).

Dewey, J. (1910), How We Think, Boston, Heath.

Duffy, T.M. (1992), The Strategic Teaching Framework, Bloomington, IN.

Duffy, T.M. (in press), 'Strategic teaching framework: an instructional model for learning complex, interactive skills' in Dill, C. and Romiszowski, A. (eds), Encyclopedia of Educational Technology, Englewood NJ, Educational Technology Press.

Duffy, T.M. and Bednar, A.K. (1991), 'Attempting to come to grips with alternative perspectives', Educational Technology, 31 (9), 12-15.

Dunlap, J.C. (1995), 'Using constructivist training environments to meet long-term strategic training needs', paper presented at the Annual Conference of the Association for Educational Communications and Technology, Anaheim CA.

Dunlap, J.C. and Grabinger, R.S. (1992), 'Designing computer-supported intentional learning environments', paper presented at the Annual Conference of the Association for the Development of Computer-Based Instructional Systems, Norfolk VA.

Dunlap, J.C. and Grabinger, R.S. (1993), 'Computer-supported intentional learning 
environments: definition and examples', paper presented at the Annual Conference of the Association for Educational Communications and Technology, New Orleans LA.

- Farnham-Diggory, S. (1992), Cognitive Processes in Education (second edition), New York, Harper Collins.

Feuerstein, R. (1979), Instrumental Enrichment, Baltimore MD, University Park.

Forman, G. and Pufall, P. (eds) (1988), Constructivism in the Computer Age, Hillsdale NJ, Lawrence Erlbaum.

Fosnot, C. (1989), Inquiring Teachers, Inquiring Learners: A Constructivist Approach for Teaching, New York, Teacher's College Press.

Frederiksen, J.R. and Collins, A. (1989), 'A systems approach to educational testing, Educational Researcher, 18, 27-32.

Gayeski, D.M. (ed) (1995), Designing Communication and Learning Environments, Englewood Cliffs NJ, Educational Technology Publications.

Goldman, S.R., Pellegrino, J.W. and Bransford, J. (1994), 'Assessing programs that invite thinking' in Baker, E. and O'Neill, H. F. J. (eds), Technology Assessment in Education and Training (pp. $\mathrm{x}-\mathrm{y}$ ), Hillsdale NJ, Lawrence Erlbaum.

Goldman, S.R., Petrosino, A., Sherwood, R.D., Garrison, S., Hickey, D., Bransford, J.D. and Pellegrino, J.W. (1992), 'Multimedia environments for enhancing science instruction', paper presented at the NATO Advanced Study Institute on Psychological and Educational Foundations of Technology-Based Learning Environments, Kolymbari, Greece.

Goodman, N. (1984), Of Mind and Other Matters, Cambridge MA, Harvard University Press.

Grabinger, R.S. and Dunlap, J.C. (1994a), 'Implementing rich environments for active learning: a case study', paper presented at the Annual Conference of the Association for Communications and Technology, Nashville LA.

Grabinger, R.S. and Dunlap, J.C. (1994b), 'Technology support for rich environments for active learning', paper presented at the Annual Conference of the Association for Communications and Technology, Nashville LA.

Gurney, B. (1989), Constructivism and Professional Development: A Stereoscopic View, ERIC Document ED $305259,1-28$.

Hannafin, M.J. (1992), 'Emerging technologies, ISD, and learning environments: critical perspectives', Educational Technology Research and Development, 40 (1), 49-63.

Honebein, P.C., Duffy, T.M. and Fishman, B.J. (1993), 'Constructivism and the design of learning environments: context and authentic activities for learning, in Duffy, T.M., Lowych, J. and Jonassen, D.H. (eds), Designing Environments for Constructive Learning, Hillsdale NJ, Lawrence Erlbaum.

Jacobson, M.J. (1994), 'Issues in hypertext and hypermedia research: toward a framework for linking theory-to-design', Journal of Educational Multimedia and Hypermedia, 3 (2), 141-54. 
Jacobson, M.J. and Spiro, R.J. (1991), 'Hypertext learning environments and cognitive flexibility: characteristics promoting the transfer of complex knowledge', paper presented at the International Conference on the Learning Sciences, Evanston IL.

Jacobson, M.J. and Spiro, R.J. (1992), 'Hypertext learning environments, cognitive flexibility, and the transfer of complex knowledge: an empirical investigation', paper presented at the Annual Meeting of the American Educational Research Association, San Francisco CA.

Jonassen, D.H. (1994b), 'Sometimes media influence learning', Educational Technology Research and Development, 42 (2).

Jonassen, D.H. (1994c), 'Thinking technology: toward a constructivist design model', Educational Technology, 34 (3), 34-7.

Kozma, R. (1994), 'Media attributes', Educational Technology Research and Development, $42(2)$.

Lebow, D. (1993), 'Constructivist values for instructional systems design: five principles toward a new mindset, Educational Technology Research and Development, 41 (3), 4-16.

Linn, M.C. (1986), Establishing a Research Base for Science Education: Challenges, Trends, and Recommendations, report of a National Science Foundation national conference, University of California.

Lockhart, R.S., Lamon, M. and Gick, M.L. (1988), 'Conceptual transfer in simple insight problems', Memory and Cognition, 16, 36-44.

Lynton, E. (1989), Higher Education and American Competitiveness, National Center on Education and the Economy.

Lynton, E. and Elman, S. (1987), New Priorities for the University, San Francisco CA, Jossey-Bass.

Mann, L. (1979), On the Trail of Process: A Historical Perspective on Cognitive Processes and their Training, New York, Grune and Stratton.

Minstrell, J.A. (1989), 'Teaching science for understanding' in Resnick, L.B. and Klopfer, L.E. (eds), Toward the Thinking Curriculum: Current Cognitive Research (pp. 129-49), Alexandria VA, ASCD.

Morris, C.D., Bransford, J.D. and Franks, J.J. (1979), 'Levels of processing versus transfer appropriate processing', Journal of Verbal Learning and Verbal Behavior, 16, 519- 33.

National Council of Teachers of Mathematics (1989), Curriculum and Evaluation Standards for School Mathematics, Reston VA, NCTM.

Neuman, D. (1993), 'Evaluation of the Perseus project', paper presented at the 1993 National Conference of the Association for Educational Communications and Technology, New Orleans LA.

Nickerson, R.S. (1988), 'On improving thinking through instruction', Review of Research in Education, 15, 3-57. 
Palincsar, A.S. (1990), 'Providing the context for intentional learning', Remedial and Special Education, 11 (6), 36-39.

Palincsar, A.S. and Klenk, L. (1992), 'Fostering literacy learning in supportive contexts', Journal of Learning Disabilities, 25 (4), 211-25.

Perelman, L.J. (1992), 'Living in the gap between old and new: managing transitions', paper presented at the Technology in Education Conference, Steamboat Springs CO.

Perfetto, B.A., Bransford, J.D. and Franks, J.J. (1983), 'Constraints on access in a problem solving context', Memory and Cognition, 11, 24-31.

Perkins, D.N. (1991), 'What constructivism demands of the learner', Educational Technology, 31 (9), 19-21.

Resnick, L. (1987), Education and Learning to Think, Washington DC, National Academy Press.

Resnick, L.B. and Klopfer, L.E. (eds) (1989), Toward the Thinking Curriculum: Current Cognitive Research, Alexandria VA, ASCD.

Ridley, D.S., Schutz, P.A., Glanz, R.S. and Weinstein, C.E. (1992), 'Self-regulated learning: the interactive influence of metacognitive awareness and goal-setting', Journal of Experimental Education, 60 (4), 293-306.

Robertson, W.C. (1990), 'Detection of cognitive structure with protocol data: predicting performance on physics transfer problems', Cognitive Science, 14, 253-80.

Roth, W.-M. (1990), Collaboration and Constructivism in the Science Classroom, ERIC Document 318 631, 1-39.

Savery, J.R. and Duffy, T.M. (1994), 'Problem based learning: an instructional model and its constructivist framework', Educational Technology (August).

Scardamalia, M. and Bereiter, C. (1991), 'Higher levels of agency for children in knowledge building: a challenge for the design of new knowledge media', The Journal of the Learning Sciences, 1 (1), 37-68.

Scardamalia, M., Bereiter, C., McLean, R.S., Swallow, J. and Woodruff, E. (1989), 'Computer-supported intentional learning environments', Journal of Educational Computing Research, 5 (1), 51-68.

Schoenfeld, A.H. (1989), 'Teaching mathematical thinking and problem solving' in Resnick, L.B. and Klopfer, L.E. (eds), Toward the Thinking Curriculum: Current Cognitive Research (pp. 83-103), Alexandria VA, ASCD.

Segal, J., Chipman, S. and Glaser, R. (eds) (1985), Thinking and Learning Skills: Relating Instruction to Basic Research, vol. 1, Hillsdale NJ, Lawrence Erlbaum.

Shank, R.C. (1990), 'Case-based teaching: four experiences in educational software design', Interactive Learning Environments, 1 (4), 231-53.

Slavin, R.E. (1991), 'Synthesis of research on cooperative learning', Educational Leadership, 48 (5), 71-82. 
Spiro, R.J., Feltovich, P.L., Jacobson, M.J. and Coulson, R.L. (1991), 'Cognitive flexibility, constructivism, and hypertext: random access instruction for advanced knowledge acquisition in ill-structured domains', Educational Technology, 31 (5), 24-33.

Tulving, E. and Thompson, D.M. (1973), 'Encoding specificity and retrieval processes in episodic memory', Psychological Review, 80, 352-73.

Von Wright, J. (1992), 'Reflections on reflection', Learning and Instruction, 2, 59-68.

Vygotsky, L.S. (1978), Mind in Society, Cambridge MA, Harvard University Press.

Weinstein, C.E., Goetz, E.T. and Alexander, P.A. (1988), Learning and Study Strategies: Issues in Assessment, Instruction, and Evaluation, San Diego CA, Academic Press.

Wheatley, M. (1992), Leadership and the New Science, San Francisco CA, BerrettKoehler.

Whitehead, A.N. (1929), The Aims of Education and Other Essays, New York, Macmillan.

Wiggins, G. (1989), 'A true test: toward more authentic and equitable assessment', Phi Delta Kappan, 70, 703-13.

Williams, M.D. and Dodge, B.J. (1992), 'Tracking and analyzing learner-computer Interaction', paper presented at the 1992 National Conference of the Association for Educational Communications and Technology, New Orleans LA.

Williams, S.M. (1992), 'Putting case-based instruction into context: exämples from legal and medical education', The Journal of the Learning Sciences, 2 (4), 367-427. 